\title{
Investigation of the dynamic characteristics of turbine impeller disc of gas turbine engine using ANSYS software
}

\author{
Quoc Toan Tran, Ngoc Thanh Huynh*, Thanh Quyet Pham
}

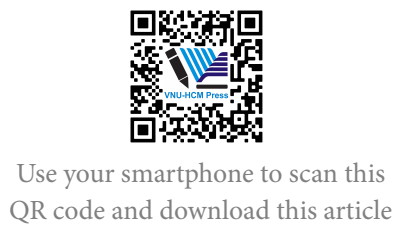

QR code and download this article

\begin{abstract}
During the operation of a gas turbine engine, the rotors including the impellers and the impeller discs of the turbine part are susceptible to damage because of its oscillation. This requires that reducing of oscillation and the impact of the oscillation on the impeller disc should be paid attention specifically in the design and manufacturing process of the turbine impeller disc. Currently, there are a lot of studies assessing the effects of oscillation on turbine disc as well as introducing modern technological innovations to improve durability, working life and manufacture cost of turbine disc part. In this paper, the authors present the research of factors affecting the impeller disc oscillation through the study of the dynamics of its constituent components ... Furthermore, this paper also presents a theoretical analysis of the formation of oscillation in the impeller disc. On the basic, a mathematical model of disc oscillation is set up to give the free oscillation equations, the equation for calculating the oscillation frequency and spectral characteristics of the individual oscillation. The authors set up an experiment model and carried out the test in order to obtain the characteristics of oscillation patterns and specific frequencies of the disc. The specific oscillation of the impeller disc, its individual oscillation, as well as the impact of the factors occurring in the operating of the disc was calculated by using ANSYS simulation software. By creating a three - dimensional model of the turbine disc of gas turbine engine ДР76, the individual oscillation values in a variety of engine operation modes were calculated to compare with the actual value while the engine is operating. The results have a good agreement with the measured values. This affirms the advantages and prospects in applying ANSYS software to the design and manufacture of the turbine impeller disc. Key words: turbine impeller disc, oscillation, low pressure turbine, turbine blades, gas turbine engine
\end{abstract}

Faculty of Electro-mechanics, Vietnam Naval Academy, Vietnam

\section{Correspondence}

Ngoc Thanh Huynh, Faculty of Electro-mechanics, Vietnam Naval Academy, Vietnam

Email: ngockhangminh269@gmail.com

History

- Received: 12-9-2019

- Accepted: 30-12-2020

- Published: 22-01-2021

DOI : 10.32508/stdjet.v3iSI3.639

\section{Check for updates}

\section{Copyright}

(c) VNU-HCM Press. This is an openaccess article distributed under the terms of the Creative Commons Attribution 4.0 International license.

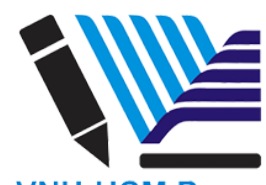

VNU-HCM Press

\section{INTRODUCTION}

The rotating blades of a compressor or turbine in a gas turbine engine is made up of blades installed on the impeller disc. In particular, the impeller disc needs to be designed, manufactured and installed to ensure its reliability and safety regarding the strict standards. If damage occurs during the operating process of the impeller disc, it will not only damage the motor but also endanger operators and other equipment. One of the causes for the impeller disc failure is due to its oscillation. Thus, the impeller disc was designed and constructed with particular concern to minimize the oscillation and its impingement on the disc.

To increase the service time of the engine as well as shorten the production cost, gas turbine manufacturers around the globe are constantly improving technology. In which the monolithic casting impeller is an advanced technology that helps bring down the impeller mass, increasing its life by reducing the shock force on the connection the blades to the rotating disc $^{1}$. Nevertheless, this type of monolithic casting impeller disc reduces its damping effectiveness, which causes the oscillation force to increase significantly. In order to resolve this problem, it is necessary to look into these factors affecting the oscillation of the impeller disc.

In order to evaluate the factors that affect the oscillation of the impeller disc, it is necessary to study the dynamic properties of its constituent components. With the aim of reducing costs as well as simplifying the design and manufacture of the impeller disc, we carry out the simulation using ANSYS software to calculate the specific oscillations and the impact of factors occurring while the engine is operating. We have created a three-dimensional (3D) model of the impeller disc of the low pressure turbine for the gas turbine engine ДР76 ${ }^{2}$ using ANSYS software. The individual oscillation values in some engine operating modes were calculated to compare with the actual values while the engine is operating. The research results are close to the actual working of the turbine impeller disc, this affirms the advantages and prospects in applying ANSYS software to the design and manufacture of turbine Technology; 3(SI3):SI81-SI88. 
impeller disc.

\section{RINCIPLES AND MATHEMATICAL MODEL}

\section{Principles}

The turbine impeller disc consists of the rim of the $\operatorname{disc}^{3}$, the hub and the flange support (Figure 1). On the rim of the disc, there are impeller blades which external forces are transferred to the disc such as: thermal expansion, centrifugal force, oscillatory force, and other factors (foreign objects, dust, salt, water, etc.).

The surface of the disc extends from the rim of the disc to the center of the disc, usually in the form of a cone or a cylinder, where in the center of the disc there is a hole for fitting with the shaft, the part attached to that axis of the disc is called the rotor blade. The selection of the shape of the disc was calculated based on each type of engine and the durability requirements of the disc.

The impeller disc is like an elastic object with a myriad of shapes and specific oscillation frequencies. The pattern of oscillation is identified by the number of diameter and circular shaped nodes.

Disc oscillations can be split into three groups:

+ The first group is the node lines in the form of concentric circles. The characteristic of these forms is the impact of the axial forces that cause the shaft to oscillate axially, increasing the pressure on the bearings. Conversely, when the axis oscillated along the axis, it will create node circles.

+ The second group corresponds to the diameter, forms and the shape of circles. This type of oscillation produces a torque that results in a dynamic imbalance being transmitted to the shaft in the form of a variable direction torque that causes various types of oscillations to bend the rotor.

+ The third group is a form of oscillation with closedloop symmetry, they are completely balanced. In this form of oscillation on the disc will form a few nodes in diameter combined with circle nodes.

It should be noted that all types of impeller oscillations lead to changes in axial clearance among the nozzle vanes. This leads to rotor crashes with the stator and damages the blades.

\section{Mathematical model}

Investigation of the oscillating impeller disc with constant thickness

In order to investigate the spectrum of the specific forms and the individual oscillation frequencies of the impeller disc, we conducted the investigation on an

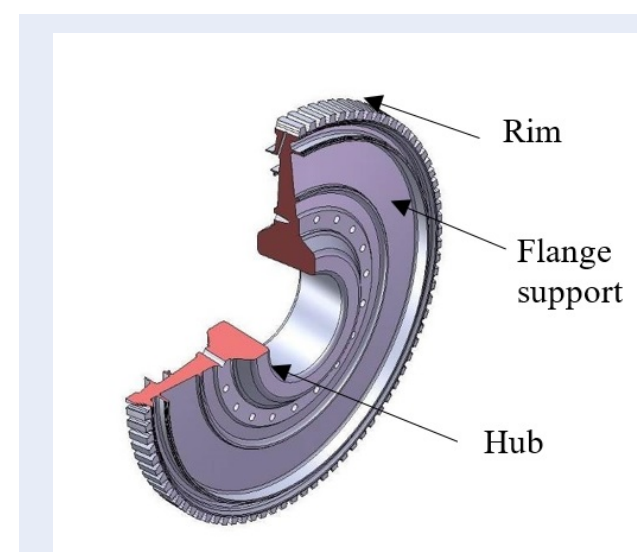

Figure 1: Design of turbine impeller disc

impeller disc with constant thickness. By this investigation, we can base on its regularity to find the characteristics of any impeller disc with any types of flange support.

In most cases, the flange support can be considered as a circular plate. From the theory of oscillation of a linear elastic object, we know that the free oscillation of any particular shape obeys the law of harmonic oscillation ${ }^{4}$ :

$$
v(\bar{a}, t)=w(\bar{a}) \cdot \cos \left(w_{0} \cdot t+\gamma\right)
$$

where:

$v(\bar{a}, t)$ : movement of points of the object; $w(\bar{a})$ : amplitude shifting points of the object;

$\bar{a}$ : vector determines the coordinates of the points of the object;

$w_{0}$ : specific frequency;

$\gamma$ : initial phase.

The differential equation of free oscillations of a circular plate with constant thickness (Figure 2) has the form:

$$
\begin{aligned}
& \triangle^{2} \cdot \triangle^{2} \cdot w-k^{4} \cdot w=0 \\
& \triangle=\frac{1}{r^{2}} \cdot \frac{\partial^{2}}{\partial r}+\frac{1}{r} \cdot \frac{\partial}{\partial}+\frac{\partial^{2}}{\partial r^{2}}
\end{aligned}
$$

where: $\Delta$-Laplace differential operator; $\mathrm{w}=\bigotimes(\mathrm{r} . \varphi)$-amplitude oscillations.

$$
k^{4}=\frac{\rho \cdot \delta \cdot R^{4} \cdot \omega_{0}^{2}}{D}
$$

where: $\rho$ - density of material;

$\delta$ - thickness of the disc;

$\mathrm{R}$ - outer radius of the disc;

$D=\frac{E . \delta^{3}}{12\left(1-\mu^{2}\right)}$ - stiffness;

$\mu$ - Poisson's coefficient;

$\mathrm{E}-$ modulus of elasticity. 
For a circular plate with constant thickness, the solution to Equation (2) will be:

$$
w(r, \varphi)=w_{m}(r) \cdot \cos (m \varphi)
$$

in which:

$$
\begin{aligned}
w_{m}(r) & =A . I_{m}(k r)+B . Y_{m}(k r) \\
& +C . I_{m}(i k r)+D . Y_{m}(i k r) ;
\end{aligned}
$$$$
I_{m}(k r), I_{m}(i k r), Y_{m}
$$

are Bessel functions of type 1 with real and complex variables $(i \sqrt{-1}) . \quad \mathrm{m}=0,1,2,3, \ldots \infty ; \mathrm{A}, \mathrm{B}, \mathrm{C}, \mathrm{D}$ -are constants determined according to the initial boundary conditions.

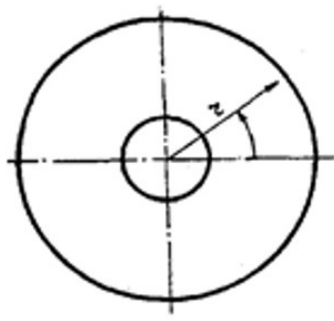

Figure 2: Circular plate with constant thickness
Calculations are performed on impeller disc with a fixed inside radius $r_{0}$ and a free outside radius $R$. In this case, the boundary conditions would be:

If $r=r_{0} \cdot w\left(r_{0}\right)=0$, then: $\frac{\partial w}{\partial r}=0$.

If $r=R \cdot R(M)=0$, then: $Q(R)=0$.

Using these boundary conditions along with equation (2) for each $m$ value, we can obtain a system of four homogeneous first order equations corresponding to the constants A, B, C, D and the formula to Calculate the frequency of the disc will be as following:

$$
\omega_{0}=\left(\frac{k}{R}\right)^{2} \cdot \sqrt{\frac{D}{\delta \cdot \rho}}
$$

As mentioned above, the possible value $m$ is from 0 to $+\infty$. From the formula (4), the value $m$ corresponds to the number of shear waves on the circle of the disc. By using this way, each level of the individual motion of the circular plates will have a myriad of unique oscillations with different number of shear waves distributed on the circular disc. In addition, each $m$ value also corresponds to a multitude of individual oscillations with a number of different circular node paths. The spectrum of the individual forms (nodal lines) of the circular plate is shown in Figure 3 and they can continue to grow to the right or down regarding the number of diameter nodes and the number of circular nodes $n$.
Thus, any particular form of the specific oscillating of impeller disc can be characterized by two integer values $m$ and $n$. Each of these specific oscillation modes has a specific oscillation frequency. Formula (5) can be rewritten as:

$(k r), Y_{m}\left(i k r_{\omega_{0 m n}}=\left(\frac{k_{m n}}{R}\right)^{2} \cdot \sqrt{\frac{D}{\delta . \rho}}\right.$

where $k_{m n}$ (according to the ratio between the radius $\propto=\frac{r_{0}}{R}$ ) from Fig. 3a.

For other conditions, when a circular plate is attached, the spectrum of the individual oscillations types has the same result as in Figure 3b. The specific oscillation frequency can be calculated according to equation (6), in which the value of $k_{m n}$ should be determined in accordance with the boundary conditions set out for different cases when fixing a circular plate with constant thickness.

\section{Spectral characteristics of individual disc movements}

The spectrum of the individual motions of any disc can be calculated from the table in Figure $3 b$.

The different feature of any individual motion when $m \neq 0$ (the slash in Figure $3 b$ ) is the position of the diameter-shaped node lines corresponding to the unknown disc and only depends on the initial conditions.

According to the theory of oscillation of a linear elastic object, any specific frequency is determined by the object and the form of oscillation. Each specific frequency with $\mathrm{m} \neq 0$ corresponds to not only one but two similar types of oscillation.

If the solution of equation (2) is a form of oscillation with a function:

$$
w_{m}^{*}(r \varphi)=w_{m}(r) \cos (m \varphi)
$$

its solution will be a function:

$$
w_{m}^{* *}(r \varphi)=w(r) \sin (m \varphi)
$$

These two types of linear oscillations are not interdependent but they are similar and have a common oscillation frequency. Therefore, when there is a free oscillation corresponding to the natural frequency $\bigotimes_{0 n}$, it always happens simultaneously that the oscillations are determined according to these two formulas.

From these equations (1), (7) and (8), so:

$$
\begin{aligned}
& v_{m}^{*}(r, \varphi, t)+v_{m}^{* *}(r, \varphi, t)=w_{m}(r) \times \\
& {\left[A^{*} \cos (m \varphi) \cos \left(\omega_{0 m} t+\gamma_{m}^{*}\right)+\right.} \\
& \left.A^{* *} \sin (m \varphi) \cos \left(\omega_{0 m} t+\gamma_{m}^{* *}\right)\right]
\end{aligned}
$$

where $A^{*}$ and $A^{* *}$ are constants that determine the absolute marginal value of oscillations of one form 


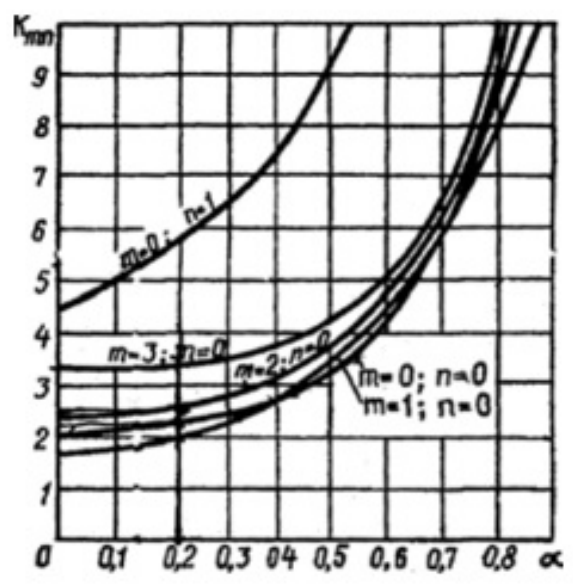

\section{a) The spectrum of the individual forms (nodal lines)}

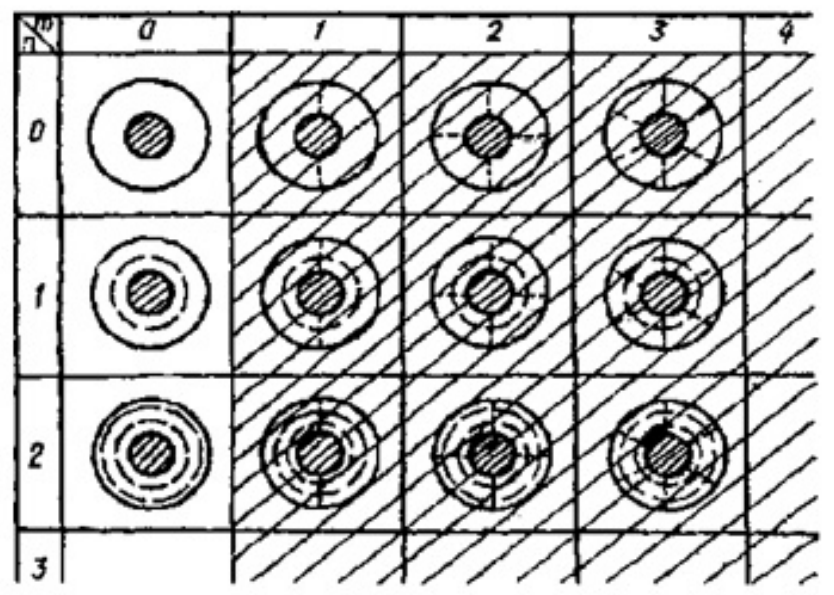

\section{b) The dependency of the frequency coefficients and diameters}

Figure 3: Spectrum of specific modes of oscillation and the relationship between frequency coefficient and diameters

and the other respectively. They depend on the initial boundary conditions. The initial phases $\gamma_{m}^{*}$ and $\gamma_{m}^{* *}$ determine the displacement during one oscillation corresponding to the other having the same oscillation frequency. They also depend on the initial conditions. In a particular case, if $\gamma_{m}^{*}=\gamma_{m}^{* *}=\gamma_{m}$, the oscillations will have same phase; the motion are then determined in the following form:

$$
\begin{aligned}
& v_{m}(r, \varphi, t)=w_{m}(r)\left[A^{*} \cos (m \varphi)\right. \\
& \left.\quad+A^{* *} \sin (m \varphi)\right] \cos \left(\omega_{0 m} t+\gamma_{m}\right)
\end{aligned}
$$

In this case, the position of the diameter form nodes will be relative to the disc, and their relative distribu- tion will depend on the values of $A^{*}$ and $A^{* *}$ respectively. For example:

If $A^{*}=A^{* *}=B$, but $y_{m}^{*}=y_{m}^{*}=\frac{\pi}{2}$, then:

$$
v_{m}=(r \varphi t)=A w_{m}(r) \cos (m \varphi+\omega t)
$$

With the initial conditions, we obtain the same amplitude value of these two types of oscillation and the relative displacement over time in the four oscillation cycles, the diameter-shaped node lines will rotate with angular velocity:

$$
\frac{\partial \varphi}{\partial t}=\frac{\omega_{0 m}}{m}
$$

In the general case of initial conditions, the sign of the disc when oscillating with the frequency $\bigotimes_{0 m}$ may be 
expressed as equations (10) and (11).

The spectral characteristics of the individual movements of a circular disc when $\mathrm{m} \neq 0$ are expressed corresponding to the specific frequency $\bigotimes_{0 m}$ of the two modes of oscillation are the same but are not dependent on each other, this is true for any linear elastic object with symmetry axis. It is not only true for impeller discs but also for cases where the objects are rings, shafts, etc. This feature is only available when the object meets the standard conditions of symmetry. Ideal objects even have a symmetrical shaft structure but do not have absolute symmetry because they cannot eliminate technological defects in the manufacturing process.

\section{INVESTIGATION OF USING ANSYS}

\section{Materials and method}

\section{a) Equipment}

To investigate the characteristics of specific oscillation mode and frequency of the impeller disc, we have tested the device as shown in Figure 4.

The device is composed of components: fixed rack 1 , clip holder 2, electromagnetic oscillator 3, power amplifier 5 , generator 7 . To check the oscillation process of the blades, piezoelectric device 12 which tightly attached to disc 2 can be used. When the impeller disc is deformed, sensor 12 will generate signal 11 . This signal is written on an oscilloscope. on its screen, we can follow and keep track of the Lissajous lines. At the same time, from signal generator 7 , the signal will be sent to the oscilloscope with the frequency of the blade excitation. Depending on the excitation frequency values we obtain Lissajous lines with different forms. When an ellipse or a straight line appears at that point, the overlapping frequency of the forced oscillation is brought to the exciter with the specific frequency of the disc.

\section{b) Method}

To oscillate the disc, we used an electromagnetic-type vibrator fed by a variable-frequency amplifier. From the rhythmic change of the frequency, we noted the overlap between the specific frequencies of the disc and the stimulating frequencies, when the elastic oscillating system (disc) resonates with the excitation frequency. This indicated by the oscillation points with a sudden increase in amplitude recorded by the oscilloscope.

According to the theory of oscillation of the elastic system, each specific oscillation frequency of the system has a specific form of oscillation. Here, the determination of the oscillation of the disc is done by the sand-picture method, by creating a layer of sand on

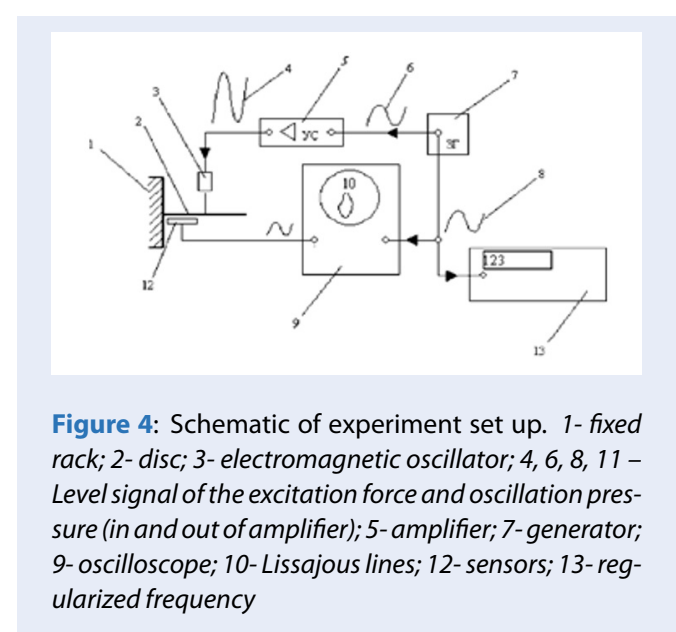

the surface of the disc. When there is a resonant oscillation of the disc with the exciter, the sand will form on the sand layer at which sand will accumulate the most. From the analysis of the position of the node lines, it is possible to find the amplitude and intensity of the disc oscillation according to its oscillation form. To keep changing the excitation frequency until the resonance point $(<10000 \mathrm{~Hz})$, we will receive the next frequency and specific oscillation of the disc.

\section{Finite element method in ANSYS}

In order to provide an investigation method and find specific frequencies, types of disc oscillations without using real impeller and costly measurement equipment, we recommend the use of ANSYS software ${ }^{5}$. ANSYS is a finite element analysis software with high accuracy results.

In this paper, we created an impeller disc model that attaches to the low pressure turbine rotor of the gas turbine engine ДР76 by the ANSYS (Figure 5). The parameters of the disc are according with the dimensions of impeller disc of the low pressure turbine in the ДР76 engine (Table 1$)^{2}$ :

- inner radius: $r_{0}=75 \mathrm{~mm}$

- outer radius: $\mathrm{R}=179 \mathrm{~mm}$

- thickness of flange support: $\delta=20 \mathrm{~mm}$

After creating the disc model, we inputted the material parameters for the impeller disc and the corresponding axis:

We proceed to create a finite element grid for the disc and the axis with hexagon elements (Figure 6). Then, we fix the two shaft ends and calculate by changing the excitative frequency value to obtain the specific oscillator frequencies $(<10000 \mathrm{~Hz})$. 


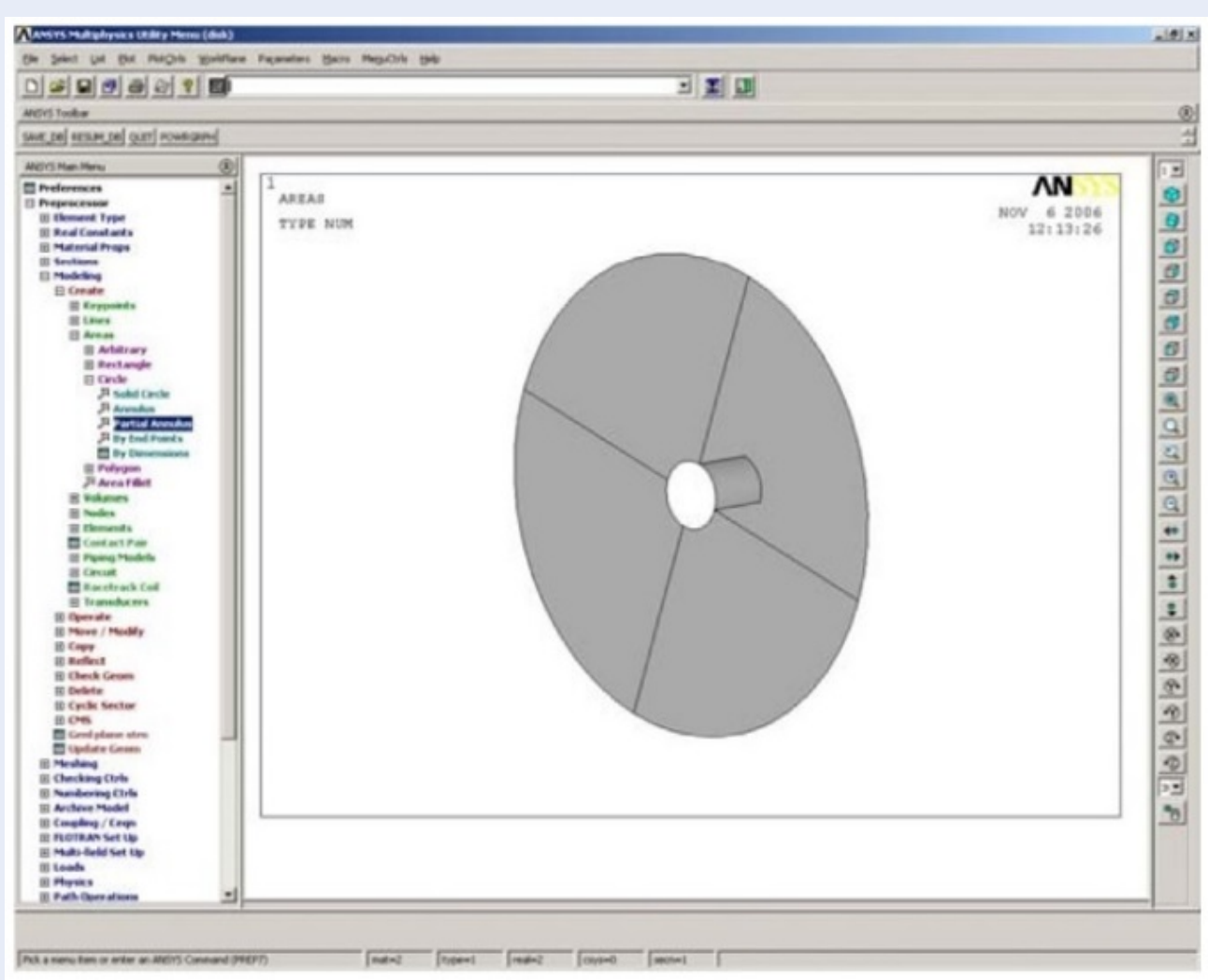

Figure 5: Simulation of impeller disc in the engine $Д Р 76^{2}$

Table 1: The material parameters for the impeller disc and the rotor of turbine ${ }^{6}$

\begin{tabular}{lll}
\hline Parameters & Impeller & Rotor \\
Modulus of elastic Young $(\mathrm{E})$ & $2.10^{11} \mathrm{~Pa}$ & $2.10^{10} \mathrm{~Pa}$ \\
Density $(\rho)$ & $7800 \mathrm{Kg} / \mathrm{m}^{3}$ & $7800 \mathrm{Kg} / \mathrm{m}^{3}$ \\
Poisson coefficient $(\mu)$ & 0.3 & 0.3 \\
\hline
\end{tabular}

\section{RESULTS AND DISCUSSION}

The investigation results of the oscillation characteristics of the disc by experiment and by ANSYS software are shown in Figure 7. The values when performing calculations to determine the specific oscillation and frequency modes of the impeller disc has a constant profile and good agreement between measured and simulated results with ANSYS software.

With the view to reduce costs as well as simplify the design and manufacture of the impeller disc, we conducted the experiment and simulation in ANSYS software. Both obtained results have good agreement in accordance with the theoretical basis of the oscillation characteristics of impeller disc in gas turbine engine ДР76.

\section{CONCLUSIONS}

The paper presented theoretical analyzes of the formation of oscillation on the turbine disc. In addition, establishing a mathematical model of disc oscillation to give the free oscillation equations, the equation for calculating the oscillation frequency and the features of spectral specific oscillation.

The paper also showed the use of testing method and using ANSYS software to calculate and simulate. Then, the results of the two methods above were compared and the results were nearly identical, in accordance with the oscillation characteristics of impeller disc in the gas turbine engine ДР76. It can be said that the use of ANSYS software in the design and manufacture of turbine impeller disc is completely reliable. 


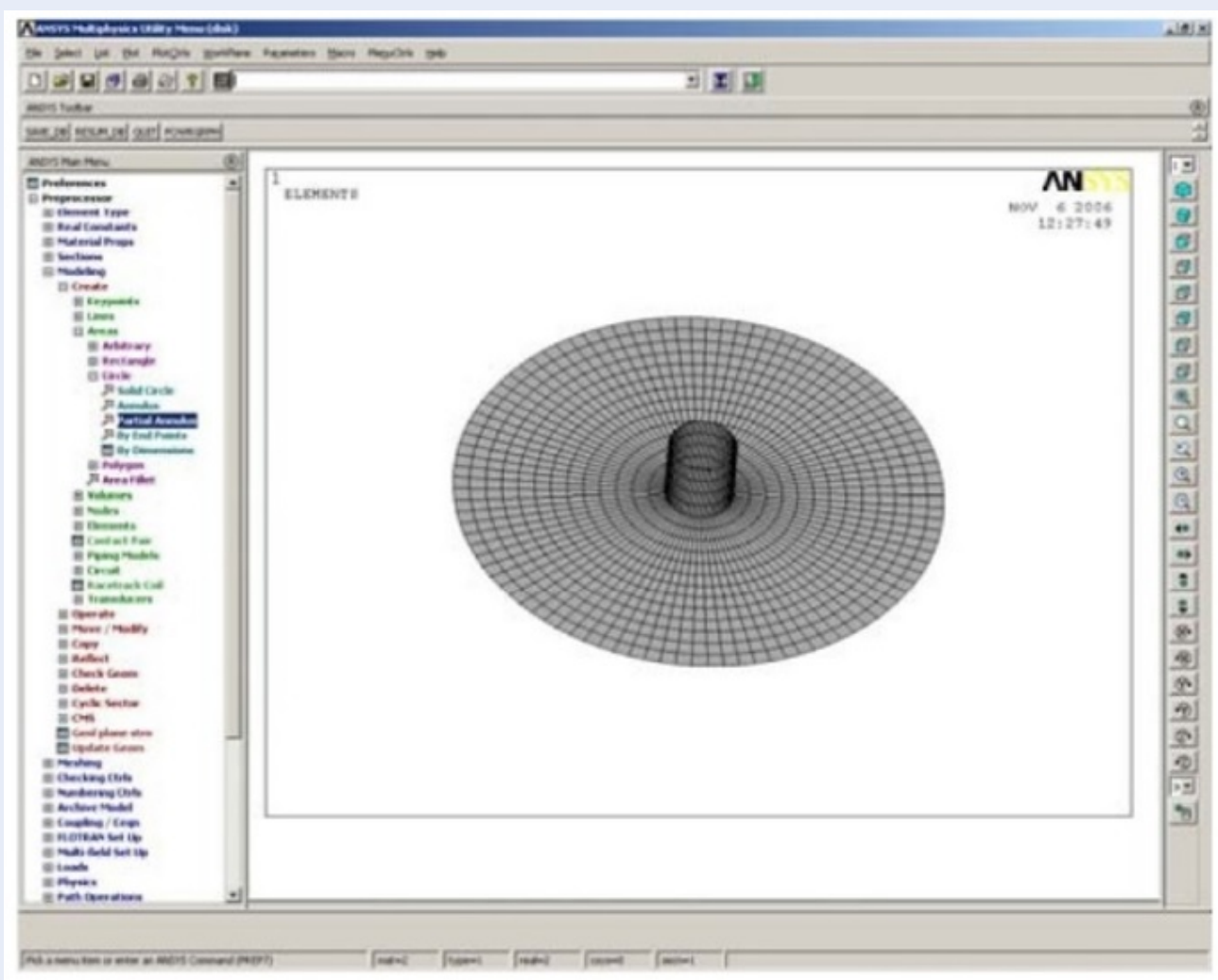

Figure 6: Finite element grid of the disc and the rotor ${ }^{5}$

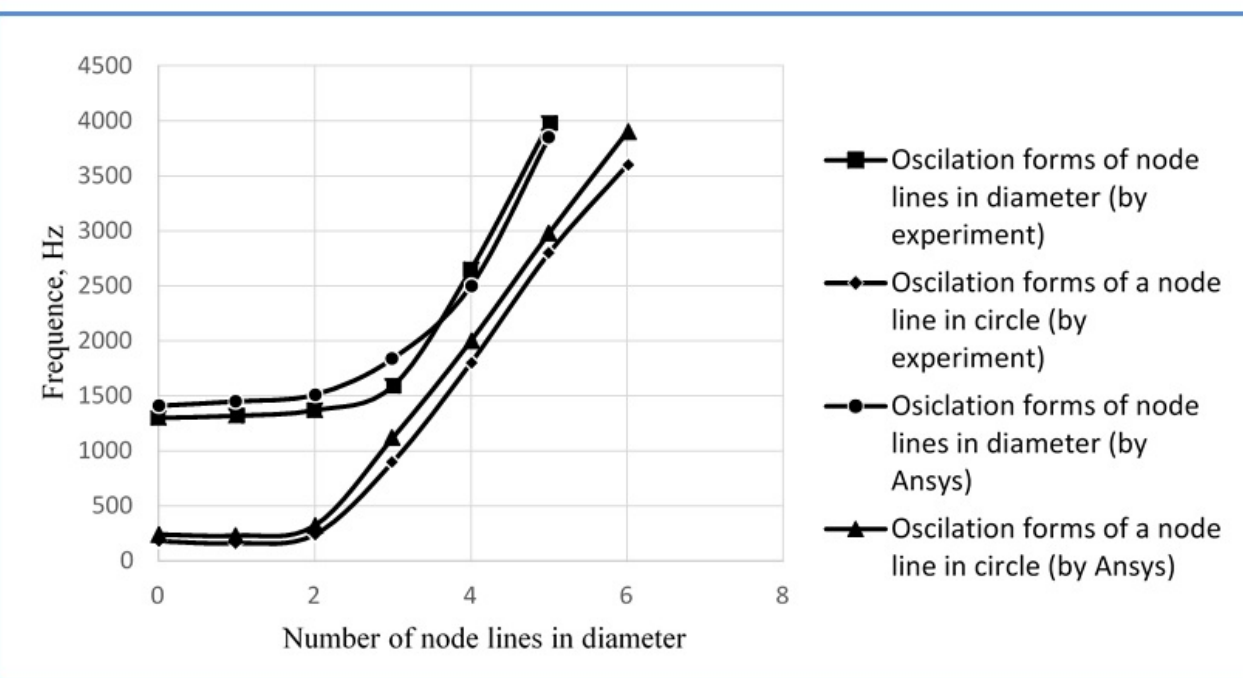

Figure 7: Investigation results on oscillation characteristics of low pressure turbine of impeller disc in engine ДР76 
The author has devised a method to conduct the oscillation characteristics of impeller discs in addition to traditional testing methods. Using ANSYS simulation software with finite element method simplifies the research process, shortens time, saves costs and brings accurate results. This is a development direction prospects in research to improve the stability and durability of impeller discs in gas turbine engines.

\section{AUTHOR CONTRIBUTIONS}

All authors contributed equally to this work. All authors have read and agreed to the published version of the manuscript.

\section{CONFLICT OF INTEREST}

We declare that there is no conflict of whatsoever involved in publishing this research.

\section{REFERENCES}

1. ИВАНОВ В.П. КОЛЕБАНИЯ РАБОЧИХ КОЛЕС ТУРБОМАШИН МАШИНОСТРОЕНИЕ. 1983;

2. ЗАВОД "ЗОРЯ-МАШПРОЕКТ", ТЕХНИЧЕСКОЕ ОПИСАНИЕ ДВИГАТЕЛЯ ДР76, НИКОЛАЕВ. 2009;

3. ВЬЮНОВ СА, ГУСЕВ Ю.И. КАРПОВ А.В. И ДР., ПОД ОБЩ РЕД. Д-РА ТЕХН. НАУК ХРОНИНА Д. В. КОНСТРУКЦИЯ И ПРОЕКТИРОВАНИЕ АВИАЦИОННЫХ ГАЗОТУРБИННЫХ ДВИГАТЕЛЕЙ, МАШИНОСТРОЕНИЕ. 1989;

4. Бабаков И.М. Теория колебаний, Издание трерье стереотипное. 1968 .

5. ANSYS. ANSYS CFX-Solver Modeling Guide. ANSYS Inc. 2010;

6. Фока АА. Судовой механик том 1, транспортная академия Украины, Одесса, Украины. 2008;. 